\title{
EFEKTIVITAS ZAKAT DALAM MENGURANGI KEMISKINAN DI JAWA TIMUR MENGGUNAKAN TEKNIK BASIC NEEEDS DEFICIENCY INDEX (BNDI)'
}

\author{
Arum Fatmawati \\ Departemen Ekonomi Syariah-Fakultas Ekonomi dan Bisnis-Universitas Airlangga \\ Email: Fatmawati.arum@gmail.com \\ Raditya Sukmana \\ Departemen Ekonomi Syariah-Fakultas Ekonomi dan Bisnis-Universitas Airlangga \\ Email: Raditya-s@feb.unair.ac.id
}

\begin{abstract}
:
This research aims to test the role of zakat to reduce poverty in the East Java period 2015-2017 by using the index that was recently developed, Basic Needs Deficiency Index. The research method used is qualitative approach with case study strategy. This research formulated BNDI index to measure the deficiency and effectiveness of zakat in resolving poverty. Data required is the total population that its income was below the poverty line in every city of East Java, and also total zakat, which was distributed by BAZNAS East Java in every city of East Java. The results obtained from the BNDI calculation have been able to explain the effectiveness of zakat for reducing poverty and inequality in East Java. The result of calculation, which was a high value or approaching value 1, explains that zakat that was distributed by BAZNAS East Java is not effective in reducing poverty in East Java. Furthermore, the result of this research shows that some cities had the highest BNDI and lowest BNDI as well. Hopefully, this result could be considered to use by the policymaker to improve the effectiveness of zakat in reducing poverty.
\end{abstract}

Keywords: Zakat, Poverty, Basic Needs Deficiency Index (BNDI)

\section{PENDAHULUAN}

Data dari PBB menunjukkan setiap sepuluh detik ada satu orang yang kehilangan nyawa karena kelaparan atau penyebab lain yag berhubungan dengan kekurangan pangan, sandang, papan, dalam hal ini yang dimaksud karena kemiskinan. Ironisnya, mayoritas yang meninggal adalah anak-anak. Pada dasarnya, bumi ini menyediakan sumber daya atau makanan yang cukup bagi manusia seperti firman Allah dalam surat Al-Baqarah ayat 2 yang artinnya "(Dialah) yang menjadikan bumi sebagai hamparan bagimu dan langit sebagai atap, dan Dialah yang menurunkan air (hujan) dari langit, lalu Dia hasilkan dengan (hujan) itu buah-buahan sebagai rezeki untuk kalian. Karena itu janganlah kamu mengadakan tandingan-tandingan bagi Allah, padahal kamu mengetahui. Namun terkadang, kondisi kemiskinan yang parah membuat mereka tidak mampu membeli makanan yang menyehatkan diri dan memenuhi gizi sehingga terjadi kasus kekurangan gizi hingga kematian.

Di Indonesia sendiri, kemiskinan merupakan masalah terbesar meskipun dalam beberapa tahun terakhir menunjukan tren yang menurun sedikit demi sedikit.

Dari data Badan Pusat Statistik (BPS) Tahun 2016, Jawa Timur menjadi

\footnotetext{
${ }^{1}$ Jurnal ini merupakan bagian dari skripsi Arum Fatmawati, NIM: 041211432011 , yang diuji pada tanggal 18 Januari 2019.
} 
provinsi tertinggi menyumbang angka kemiskinan di Indonesia, sekitar 4.7 juta jiwa penduduk miskin ada di Jawa Timur. Memiliki wilayah terluas diantara 6 provinsi di pulau jawa dan berkontribusi `4.85\% terhadap Produk Domestik Bruto Nasional.

Tabel 1.

Kabupaten/Kota dengan Persentase

Penduduk Miskin Tertinggi di Jawa Timur

\begin{tabular}{|l|l|l|l|}
\hline Kab./Kota & $\mathbf{2 0 1 5}$ & $\mathbf{2 0 1 6}$ & $\mathbf{2 0 1 7}$ \\
\hline Sampang & 25.69 & 24.11 & 23.56 \\
\hline Bangkalan & 22.57 & 21.41 & 21.32 \\
\hline Probolinggo & 20.82 & 20.98 & 20.52 \\
\hline Sumenep & 20.20 & 20.09 & 19.62 \\
\hline Tuban & 17.08 & 17.14 & 16.87 \\
\hline Pamekasan & 17.41 & 16.70 & 16.00 \\
\hline Pacitan & 16.68 & 15.49 & 15.42 \\
\hline Ngawi & 15.61 & 15.27 & 14.91 \\
\hline Bondowoso & 14.96 & 15 & 14.54 \\
\hline Lamongan & 15.38 & 14.89 & 14.42 \\
\hline
\end{tabular}

Sumber : Badan Pusat Statistik (BPS)

Data yang dirilis dari Badan Pusat Statistik (BPS) tahun 2015-2017 menunjukan Sampang menempati urutaan termiskin di Jawa Timur dengan presentase 23\%-25\% penduduk miskin. Urutan kedua dan ketiga diikuti oleh Bangkalan dan Probolinggo. Sedangkan daerah yang memiliki presentase terendah adalah kota batu, dengan presentase hanya $4.32 \%$ ditahun 2017. Dengan data diatas, dapat disimpulkan kemiskinan menjadi masalah besar bagi Indonesia terutama untuk Jawa Timur.

Indonesia, sebagai salah satu Negara yang memiliki populasi muslim terbesar Pada tahun 2016 data BPS menyebutkan sebesar 175 juta jiwa memeluk agama islam, dengan kata lain $70 \%$ dari total penduduk di Indinesia. Permasalahan dan potensi zakat adalah hal yang tak terpisahkan. Sehingga pemerintah Indonesia membentuk suatu lembaga untuk memfasilitasi penghimpunan dan penyaluran zakat. Badan Amil Zakat Nasional atau BAZNAS adalah lembaga yang memiliki fungsi menghimpun dan menyalurkan zakat,infaq dan sedekah (ZIS) secara nasional, merupakan lembaga pemerintah nonstruktural yang bersifat mandiri dan bertanggung jawab kepada Presiden melalui Menteri Agama. Dibentuk oleh pemerintah berdasarkan keputusan Presiden RI No.8 Tahun 2001 dan diperkuat oleh UU No.23 Tahun 2011 tentang pengelolaan zakat. Disisi lain, Lembaga Amil Zakat di Indonesia sangat banyak jumlahnya yang dikelola oleh pihak swasta, namun, pada penelitian ini saya berfokus pada BAZNAS sebagai lembaga/ badan resmi yang ditunjuk oleh pemerintah.

Di Jawa Timur, provinsi dengan tingkat kemiskinan absolut tertinggi , proses pengumpulan dan penyaluran zakat difasilitasi oleh BAZNAS provinsi Jawa Timur yang berkantor pusat di kota Surabaya, ibukota Jawa Timur. Di media nasional menyebutkan bahwa potensi zakat di Jawa Timur mencapai 30 Triliun, namun pada realisasinya penghimpunan dana zakat masih sangat rendah, Tentu ini 
Fatmawati, et al/Jurnal Ekonomi Syariah Teori dan Terapan Vol. 6 No. 3 Maret 2019: 568-583; EFEKTIVITAS ZAKAT DALAM MENGURANGI KEMISKINAN DI JAWA TIMUR MENGGUNAKAN TEKNIK BASIC NEEEDS DEFICIENCY INDEX (BNDI)

menjadi tugas bersama untuk mengoptimalkan potensi zakat.

Penelitian ini bermaksud melihat bagaimana efektivitas zakat dalam mengurangi kemiskinan di Jawa Timur, dengan tiga determinan utama yaitu :Konsumsi minimum untuk kebutuhan dasar (GK), jumlah zakat yang disalurkan pemerintah (BAZNAS provinsi Jawa Timur) dan jumlah orang miskin. Penelitian ini menggunakan periode 2015-2017, dengan menggunakan teknik yang baru saja dikembangkan yaitu basic needs deficiency index (BNDI). Melalui temuan dipenelitian ini, diharapkan dapat digunakan oleh para pembuat kebijakan untuk mengukur dan meningkatkan efektifvtas zakat dalam mengurangi kemiskinan serta sebagai salah satu acuan atau refrensi bagi para pembaca dan peneliti selanjutnya

II. LANDASAN TEORI

Kata efektif berasal dari bahasa inggris yaitu effective yang berarti sesuatu yang dilakukan berhasil dengan baik. Kamus ilmiah lainnya mendefinisikan efektifitas sebagai ketepatan penggunaan dan hasil guna.

Zakat dalam segi istilah adalah harta tertentu yang wajib dikeluarkan orang islam dan diberikan kepada golongan yang berhak menerimanya. Pada zaman Rasulullah SAW, Negara mempunyai kewajiban untuk menghitung zakat para warga Negara, mengumpulkan juga mendistribusikan dengan membentuk badan atau suatu lembaga zakat. Badan pegumpul zakat untuk mengumpulkan zakat kemudian di masukkan ke baitul mal, untuk penggunaan zakat ditentukan pemerintah berdasarkan ketentuan AlQuran dan hadist. Nurul Huda (2012:91) menjelaskan sejarah zakat diterapkan pada semangat ketauhidan Rasul di dalam suatu negara. Zakat sebagai salah satu sumber pendapatan primer selain ushr (hasil pertanian), pertama kali diturunkan pada tahun ke-2 Hijriah, yaitu berupa zakat fitrah, dan tahun ke-9 Hijriah turun perintah zakat mal. Menurut Amer al-Roubaie dalam buku yang berjudul Dimensi Global Kemiskinan di Dunia Muslim : Sebuah Penilaian Kuantitatif, Rasulullah SAW pernah mengangkat beberapa sahabat (Umar bin Khattab, Ibnu Qais 'Ubadah Ibn Shamit dan Mu'az Jabal) sebagai amil zakat di tingkat daerah. Sedangkan untuk pengelolaannya, Mustafa Edwin Nasution berpendapat dalam buku yang berjudul Pengenalan Eksklusif Ekonomi Islam, Rasulullah SAW memberikan contoh manajemen operasional yang bersifat teknis. Pembagian struktur amil zakat yang terdiri dari katabah; petugas yang mencatat para wajib zakat, Hasabah; petugas yang menghitung zakat, Jubah; petugas yang mengambil zakat dari muzakki, Khazanah; petugas yang menghimpun dan memelihara zakat, Qasamah; menyalurkan zakat kepada para mustahiq. 
Di Indonesia, untuk melaksanakan pengelolaan zakat, pemerintah membentuk Badan Amil Zakat Nasional (BAZNAS) bertempat di ibu kota negara. BAZNAS merupakan lembaga pemerintah non struktural yang bersifat mendiri dan bertanggung jawab kepada presiden melalui menteri. BAZNAS memiliki fungsi sebagai berikut; perencanaan pengumpulan, pendistribusian dan pendayagunaan zakat. Pengelolaan badan amil zakat diatur dalam UU RI nomor 23 tahun 2011 tentang pengelolaan zakat pasal 15 ayat (1) dinyatakan " Dalam rangka pelaksanaan pengelola zakat pada tingkat provinsi dan kabupaten/kota dibentuk BAZNAS provinsi dan BAZNAS kabupaten/kota", undang-undang ini menggantikan UU nomor 38 tahun 1999. Dan diperkuat oleh pasal 17 yang menyatakan "untuk membantu BAZNAS dalam pelaksaan pengumpulan, pendistribusian dan pendayagunaan zakat, masyarakat dapat membentuk LAZ ". Pembentukan LAZ (Lembaga Amil Zakat ) harus mendapat ijin dari menteri atau pejebat yag dibentuk menteri, dengan memenuhi persyaratan tertentu. LAZ harus melaporkan pelaksanaan pengumpulan, pendistribusian dan pendayagunaan zakat yang telah di audit kepada BAZNAS secara berkala.

Merujuk pada surat edaran dari presiden Soeharto No. B113/PRES/11/1968 dan ditindak lanjuti oleh menteri agama untuk menyusun peraturan pengelolaan zakat dan diikuti dengan aturan yang dikeluarkan pemerintah daerah untuk mendukung pengelolaan zakat. Maka, pemerintah provinsi Jawa Timur membentuk Baznas,bertempat di Islamic Centre Surabaya. Selain BAZNAS Jatim, adapula LAZ yang dibentuk oleh badan swasta atau masyarakat setempat, namun LAZ- LAZ tersebut tetap memiliki kewajiban melaporkan dana zakat kepada pihak Baznas Jatim.

Penelitian ini berfokus kepada zakat yang didistribusikan oleh BAZNAS Jawa Timur, tidak termasuk LAZ swasta lainnya yang beroperasi di Jawa Timur, berikut jumlah zakat yang didistribusikan oleh BAZNAS Jawa Timur periode 20152017.

Menurut survey yang dilakukan oleh Asia Pacific Philanthrophy Consortium (APPC) pada 2001, Indonesia sebagai negara paling tinggi se-dunia untuk mengeluarkan donasi dari harta kekayaannya dengan faktor keagamaan (Fauzia, 2008:1). Sedangkan berdasarkan penelitian yang dilakukan oleh baznas pada 2016 potensi zakat mencapai 286 Triliun, namun yang terkumpul hanya sekitar 6 Triliun pertahun atau hanya 2 persen. Potensi yang besar namun sayangnya belum terserap dengan maksimal. Dibutukan pihak-pihak terkait bersama-sama membangun sinergi yang baik seperti dengan membuat dan menjalankan kebijakan dengan bijaksana. Menurut Politik ZISWAF pada Huda (2012: 107), "Mengentas 100 keluarga miskin 
adalah dengan CSR, namun jika mengentaskan sejuta orang miskin itu namanya adalah kebijakan." Persoalan di Indonesia masih menjadi persoalan yang sangat kompleks dari segi sumber daya manusia maupun manajemennya.

Garis kemiskinan (GK) adalah batas minimum pengeluaran perkapita dalam sebulan untuk memenuhi kebutuhan minimum makanan dan non makanan atau lebih singkatnya kebutuhan standar minimum.garis kemiskinan (GK) terdiri dari garis kemiskinan makan (GKM) dan garis kemiskinan makanan (GKNM). GKM merupakan nilai pengeluaran kebutuhan minimum makanan yang disetarakan 2100 kilokalori perkapita perhari. Paket komoditi kebutuhan dasar makanan diwakili oleh 52 jenis komoditi (padi-padian, umbiumbian, ikan, daging, telur dan susu, sayuran, kacang-kacangan, buahbuahan, minyak dan lemak, dII) sedagkan GKNM adalah kebutuhan minimum untuk perumahan, sandang, pendidikan dan kesehatan.

Data dari Badan Pusat Statistik (BPS) menjelaskan presentase penduduk miskin di Jawa Timur cenderung menurun, selain itu juga dapat disimpulkan bahwa kabupaten dengan presentase tingkat kemiskinan tertinggi dari tahun ke tahun adalah kabupaten Sampang, presentasenya di atas 20\%. Selain hal tersebut, fakta menarik lainnya adalah pada tahun 2016 ada 8 kota/kabupaten mengalami kenaikan presentase penduduk miskin dari tahun sebelumnya, yaitu : Jember, Bondowoso, Probolinggo, Mojokerto, Madiun, Tuban, Kota Pasuruan, Kota Madiun. Sedangkan ditahun 2017 hanya 2 kota saja yang mengalami kenaikan yatu kota Kediri dan kota Blitar

Basic needs deficiency index (BNDI) adalah metode baru untuk mengukur pengentasan kemiskinan berfokus pada konsumsi atau belanja minimum rumah tangga orang miskin untuk kebutuhan dasar dan zakat yang didistribusikan oleh pemerintah, yang dalam penelitian ini adalah BAZNAS Jawa Timur. BNDI memungkinkan membandingkan kekurangan kebutuhan dasar antar wilayah, kota maupun kabupaten, diformulasikan sedemikian rupa untuk mengukur kekurangan dan juga efektifitas zakat dalam mengurangi kemiskinan.

The Effectiveness of zakat in alleviating poverty and inequalities, a measurement using a newly develop technique oleh Abdullah dkk (2012) menguji peran zakat dalam mengurangi kemiskinan dan ketidaksetaraan dipakistan, menggunakan teknik yang baru saja dikembangkan, yaitu Basic needs deficiency index (BNDI). Hasil yang diperoleh dari berhitungan BNDI telah mampu menjelaskan efektifitas zakat dalam mengurangi kemiskinan dan ketidaksetaraan di Pakistan. Pengukuran yang menggunakan indeks pembangunan manusia (IPM), Angka kemskinan perkepala, Gini Koefisien 
Fatmawati, et al/Jurnal Ekonomi Syariah Teori dan Terapan Vol. 6 No. 3 Maret 2019: 568-583; EFEKTIVITAS ZAKAT DALAM MENGURANGI KEMISKINAN DI JAWA TIMUR MENGGUNAKAN TEKNIK BASIC NEEEDS DEFICIENCY INDEX (BNDI)

cenderung menunjukan bahwa keaadaan kemiskinan dipakistan membaik selama dua periode. Namun hasil dari BNDI cenderung tidak membaik. Salah satu alasanya rasional secara umum pengeluaran Q1 (kemiskinan absolut) dan Q2 ( kemiskinan relatif) jauh lebih besar daripada jumlah zakat yang mereka terima dari pemerintahan selanjutnya diberikan jumlah zakat yang sama, Q2 paling menderita karna pengeluaran mereka lebih tinggi dari Q1 dengen kata lain dalam Q1 jumlah zakat yang diterima oleh mereka telah mampu menutupi sebagian besar pengeluaran kebutuhan dasar. Hasil mengguunakan Teknik BNBI sebanding dan konsisten dengan Bank Dunia (2002), Anwar dkk (2005), Anwar dan Qureshi (2002), meskipun periode dan studi berbeda.

\section{METODE PENELITIAN}

Penelitian ini menggunakan teknik yang baru saja dikembangkan, yaitu basic needs deficiency index (BNDI) untuk mengukur efektifitas zakat dalam mengurangi kemiskinan dalam suatu wilayah.

Data yang diperoleh bersumber pada Badan pusat Statistik (BPS) dan data internal Badan Amil Zakat Nasional Jawa Timur sebagai lembaga resmi yang ditunjuk oleh pemerintah Indonesia untuk mengelola zakat. Untuk menyusun BNDI periode 2015-2016 dan 2016-2017 beberapa data yang dibutuhkan adalah :

1. Jumlah penduduk yang pendapatannya di bawah garis kemiskinan. Dengan kata lain jumlah orang miskin, karna penelitian ini fokus terhadap wilayah Jawa Timur, maka jumlah orang miskin di setiap kota atau kabupaten di Jawa Timur periode 2015-2017

2. Total minimum pengeluaran untuk kebutuhan dasar. Dalam penelitian ini, kebutuhan dasarnya mengacu pada jumlah vang yang digunakan yang terbatas pada pengeluaran untuk makan,tempat tinggal, pakaian, kesehatan dan pendidikan. Dengan kata lain Garis Kemiskinan (GK) disetiap kota ataupun kabupaten di Jawa Timur

3. Jumlah zakat yang dikeluarkan, karna pemerintah menunjuk BAZNAS sebagai lembaga yang bertanggung jawab atas pengelolaan zakat di Indonesia, danpenelitian ini terfokus untuk wilayah Jawa Timur saja maka yang dimaksudkan adalah zakat yang didistribusikan oleh BAZNAS Jawa Timur di seluruh kota atau kabupaten di Provinsi Jawa Timur periode 2015-2017

Pada dasarnya BNDI adalah karya Abdullah dan AL-Maikawi (2009) dan lebih disempurnakan oleh Abdullah dkk (2012). Diawali dengan, Inseks Efisiensi Zakat berasal dari berikut :

Pertama, pengeluaran untuk kebutuhan dasar (EB) dari penduduk termiskin (Q1) yang secara matematis dinyatakan:

$$
E_{B}=\sum_{i=1}^{m} \sum_{j=1}^{n} E_{B i t}^{Q 1 j}
$$

Di mana : 
$\mathrm{i}=(1,2, \ldots \mathrm{m})$ adalah kebutuhan dasar $(\mathrm{B})$ yang dalam penelitian ini termasuk makanan, pakaian, tempat tinggal, kesehatan dan pendidikan

$j=(1,2, \ldots n)$ adalah provinsi atau wilayah dinegara tersebut

$t=$ periode waktu

Kedua, pengeluaran pemerintah untuk kemiskinan $(G)$ yang dalam penelitian ini terbatas pada pencairan zakat (Z) atau lebih tepatnya jumlah dana zakat yang dikeluarkan.

$$
G_{Z}=\sum_{j=1}^{n} G_{B i t}^{Q 1 j}
$$

Di mana : j $(1,2, \ldots$ n) dan t tetap sama seperti persamaan (1)

Ketiga, jumlah penerima zakat yang terkait dengan Q1( termiskin) dapat dinyatakan sebagai berikut:

$$
Z_{R}=\sum_{j=1}^{n} Z_{B i t}^{Q 1 j}
$$

Di mana : j $(1,2, \ldots$ n) dan t tetap sama seperti persamaan (1)

Keempat, BND diperoleh dengan mengurangi persamaan (2) dari (1) dan kemudian membagi dengan persamaan (3), seperti yang ditunjukkan dibawah ini :

$\mathrm{BND} \quad=\quad \frac{E_{B}}{Z_{R}}$

$\frac{G_{Z}}{Z_{R}}$

Akhirnya, BNDI diturunkan melalui persamaan (4), dengan persamaan :

$\mathrm{BNDI}=\frac{E_{B / Z_{R}}}{E_{B / Z_{R}}}-$

$\frac{G_{Z / Z_{R}}}{E_{B / Z_{R}}}$

Penyempurnaan lebih lanjut dari persamaan (5), dan menghasilkan persamaan akhir (6) :

BNDI = 1

$\frac{G_{Z}}{E_{B}}$

Secara umum, GZ lebih kecil dari pada EZ. Jika GZ lebih besar tentunya tidak adamasalah kemiskinan atau tidak ada masalah kekurangan kebutuhan dasar. Dengan deminian, indeks ini mengukur kekurangan dari jumlah zakat yang dikeluarkan oleh BAZNAS/ zakat yang diterima oleh penerima zakat dibandingkan dengan total pengeluaran untuk kebutuhan dasar orang miskin./penerima zakat. Seperti dalam indeks lainnya, BNDI memiliki angka skala 0-1. Indeks yang besar menyiratkan kinerja yang buruk, begitu juga sebaliknya. Berikut contoh sederhana mengilustrasikan dengan menggunakan tiga kasus hipotesis yang berbeda:

- Kasus pertama,

Jika GZ=0 DAN EZ = 1, maka BNDI adalah 1. Menyiratkan bahwa kekurangan kebutuhan dasar telah mencapai nilai maksimal, sehingga ini keadaan terburuk.

- Kasus kedua,

Jika $\mathrm{GZ}=1$ dan $\mathrm{EZ}=0$, maka BNDI adalah 0 , yang menunjukan tidak adakekurangan kebutuhan dasar, ini hal terbaik.

- Kasus ketiga,

Jika $G Z=0.5$ dan $E Z=1$, maka BNDI adalah 0.5 yang berarti kekurangan kebutuhan dasar masih bisa ditolerir.

Secara umum, BNDI dada dalam skala $0 \leq$ $B N D I \leq 1$. 
IV. HASIL DAN PEMBAHASAN

Tabel 2.

Tabel Hasil penghitungan BNDI

Kabupaten dan Kota di Provinsi Jawa

Timur tahun 2015

\begin{tabular}{|c|c|c|c|c|c|}
\hline $\begin{array}{l}N \\
0\end{array}$ & $\begin{array}{l}\text { Kota/Ka } \\
\text { b. }\end{array}$ & $\begin{array}{l}\text { Nilai } \\
\text { BNDI }\end{array}$ & No & $\begin{array}{l}\text { Kota/K } \\
\text { ab. }\end{array}$ & $\begin{array}{l}\text { Nilai } \\
\text { BNDI }\end{array}$ \\
\hline 1 & $\begin{array}{l}\text { Kota } \\
\text { Mojokert } \\
\text { o }\end{array}$ & $\begin{array}{l}0.9985 \\
33\end{array}$ & 20 & Tuban & $\begin{array}{l}0.9999 \\
67\end{array}$ \\
\hline 2 & $\begin{array}{l}\text { Kota } \\
\text { Madiun }\end{array}$ & $\begin{array}{l}0.9988 \\
3\end{array}$ & 21 & $\begin{array}{l}\text { Tulunga } \\
\text { gung }\end{array}$ & $\begin{array}{l}0.9999 \\
84\end{array}$ \\
\hline 3 & Sidoarjo & $\begin{array}{l}0.9992 \\
61\end{array}$ & 22 & $\begin{array}{l}\text { Pasurua } \\
\mathrm{n}\end{array}$ & $\begin{array}{l}0.9999 \\
84\end{array}$ \\
\hline 4 & $\begin{array}{l}\text { Kota } \\
\text { Surabay } \\
\text { a }\end{array}$ & $\begin{array}{l}0.9995 \\
25\end{array}$ & 23 & $\begin{array}{l}\text { Lumaja } \\
\text { ng }\end{array}$ & $\begin{array}{l}0.9999 \\
86\end{array}$ \\
\hline 5 & Nganjuk & $\begin{array}{l}0.9997 \\
42\end{array}$ & 24 & $\begin{array}{l}\text { Proboli } \\
\text { nggo }\end{array}$ & $\begin{array}{l}0.9999 \\
86\end{array}$ \\
\hline 6 & $\begin{array}{l}\text { Ponorog } \\
\text { O }\end{array}$ & $\begin{array}{l}0.9997 \\
69\end{array}$ & 25 & Jember & $\begin{array}{l}0.9999 \\
88\end{array}$ \\
\hline 7 & $\begin{array}{l}\text { Jomban } \\
\mathrm{g}\end{array}$ & $\begin{array}{l}0.9997 \\
92\end{array}$ & 26 & $\begin{array}{l}\text { Banyuw } \\
\text { angi }\end{array}$ & $\begin{array}{l}0.9999 \\
91\end{array}$ \\
\hline 8 & $\begin{array}{l}\text { Bojoneg } \\
\text { oro }\end{array}$ & $\begin{array}{l}0.9998 \\
15\end{array}$ & 27 & $\begin{array}{l}\text { Lamon } \\
\text { gan }\end{array}$ & $\begin{array}{l}0.9999 \\
93\end{array}$ \\
\hline 9 & Gresik & $\begin{array}{l}0.9998 \\
32\end{array}$ & 28 & Pacitan & 1 \\
\hline 10 & $\begin{array}{l}\text { Pameka } \\
\text { san }\end{array}$ & $\begin{array}{l}0.9998 \\
53\end{array}$ & 29 & Blitar & 1 \\
\hline 11 & $\begin{array}{l}\text { Kota } \\
\text { Probolin } \\
\text { ggo }\end{array}$ & $\begin{array}{l}0.9998 \\
94\end{array}$ & 30 & Kediri & 1 \\
\hline 12 & $\begin{array}{l}\text { Situbond } \\
\text { O }\end{array}$ & $\begin{array}{l}0.9999 \\
03\end{array}$ & 31 & $\begin{array}{l}\text { Maget } \\
\text { an }\end{array}$ & 1 \\
\hline 13 & $\begin{array}{l}\text { Trenggal } \\
\text { ek }\end{array}$ & $\begin{array}{l}0.9999 \\
23\end{array}$ & 32 & Ngawi & 1 \\
\hline 14 & Malang & $\begin{array}{l}0.9999 \\
28\end{array}$ & 33 & $\begin{array}{l}\text { Bangka } \\
\text { lan }\end{array}$ & 1 \\
\hline
\end{tabular}

\begin{tabular}{|l|l|l|l|l|l|}
\hline 15 & Madiun & $\begin{array}{l}0.9999 \\
32\end{array}$ & 34 & $\begin{array}{l}\text { Kota } \\
\text { Kediri }\end{array}$ & 1 \\
\hline 16 & $\begin{array}{l}\text { Sumene } \\
\mathrm{p}\end{array}$ & $\begin{array}{l}0.9999 \\
33\end{array}$ & 35 & $\begin{array}{l}\text { Kota } \\
\text { Blitar }\end{array}$ & 1 \\
\hline 17 & $\begin{array}{l}\text { Bondow } \\
\text { oso }\end{array}$ & $\begin{array}{l}0.9999 \\
44\end{array}$ & 36 & $\begin{array}{l}\text { Kota } \\
\text { Malang }\end{array}$ & 1 \\
\hline 18 & $\begin{array}{l}\text { Mojokert } \\
\text { o }\end{array}$ & $\begin{array}{l}0.9999 \\
59\end{array}$ & 37 & $\begin{array}{l}\text { Kota } \\
\text { Pasurua }\end{array}$ & 1 \\
\hline 19 & $\begin{array}{l}\text { Sampan } \\
\text { g }\end{array}$ & $\begin{array}{l}0.9999 \\
63\end{array}$ & 38 & $\begin{array}{l}\text { Kota } \\
\text { Batu }\end{array}$ & 1 \\
\hline
\end{tabular}

Tabel 3.

Tabel Hasil penghitungan BNDI Kabupaten dan Kota di Provinsi Jawa Timur tahun 2016

\begin{tabular}{|c|c|c|c|c|c|}
\hline No & Kota/Kab. & $\begin{array}{l}\text { Nilai } \\
\text { BNDI }\end{array}$ & No & $\begin{array}{l}\text { Kota } \\
\text { /Kab } \\
.\end{array}$ & $\begin{array}{l}\text { Nila } \\
\text { i } \\
\text { BND } \\
\text { I }\end{array}$ \\
\hline 1 & $\begin{array}{l}\text { Kota } \\
\text { Madiun }\end{array}$ & $\begin{array}{l}0.998 \\
725\end{array}$ & 20 & $\begin{array}{l}\text { Situb } \\
\text { ond } \\
\text { o }\end{array}$ & $\begin{array}{l}0.99 \\
990 \\
7\end{array}$ \\
\hline 2 & Sidoarjo & $\begin{array}{l}0.999 \\
164\end{array}$ & 21 & $\begin{array}{l}\text { Sum } \\
\text { ene } \\
p\end{array}$ & $\begin{array}{l}0.99 \\
991 \\
4\end{array}$ \\
\hline 3 & $\begin{array}{l}\text { Kota } \\
\text { Surabaya }\end{array}$ & $\begin{array}{l}0.999 \\
534\end{array}$ & 22 & $\begin{array}{l}\text { Sam } \\
\text { pan } \\
g\end{array}$ & $\begin{array}{l}0.99 \\
994 \\
7\end{array}$ \\
\hline 4 & $\begin{array}{l}\text { Kota } \\
\text { Proboling } \\
\text { go }\end{array}$ & $\begin{array}{l}0.999 \\
636\end{array}$ & 23 & $\begin{array}{l}\text { Kota } \\
\text { Kedir } \\
\text { i }\end{array}$ & $\begin{array}{l}0.99 \\
994 \\
7\end{array}$ \\
\hline 5 & Ponorogo & $\begin{array}{l}0.999 \\
695\end{array}$ & 24 & $\begin{array}{l}\text { Lum } \\
\text { ajan } \\
\text { g }\end{array}$ & $\begin{array}{l}0.99 \\
996\end{array}$ \\
\hline 6 & Mojokerto & $\begin{array}{l}0.999 \\
716\end{array}$ & 25 & $\begin{array}{l}\text { Ban } \\
\text { gkal } \\
\text { an }\end{array}$ & $\begin{array}{l}0.99 \\
996 \\
1\end{array}$ \\
\hline
\end{tabular}




\begin{tabular}{|c|c|c|c|c|c|}
\hline 7 & $\begin{array}{l}\text { Bojonegor } \\
\text { o }\end{array}$ & $\begin{array}{l}0.999 \\
735\end{array}$ & 26 & $\begin{array}{l}\mathrm{Nga} \\
\text { wi }\end{array}$ & $\begin{array}{l}0.99 \\
997 \\
6\end{array}$ \\
\hline 8 & Nganjuk & $\begin{array}{l}0.999 \\
748\end{array}$ & 27 & $\begin{array}{l}\text { Tuba } \\
\mathrm{n}\end{array}$ & $\begin{array}{l}0.99 \\
997 \\
6\end{array}$ \\
\hline 9 & Jombang & $\begin{array}{l}0.999 \\
759\end{array}$ & 28 & $\begin{array}{l}\text { Pasu } \\
\text { ruan }\end{array}$ & $\begin{array}{l}0.99 \\
997 \\
7\end{array}$ \\
\hline 10 & $\begin{array}{l}\text { Trenggale } \\
k\end{array}$ & $\begin{array}{l}0.999 \\
76\end{array}$ & 29 & $\begin{array}{l}\text { Lam } \\
\text { ong } \\
\text { an }\end{array}$ & $\begin{array}{l}0.99 \\
997 \\
9\end{array}$ \\
\hline 11 & Gresik & $\begin{array}{l}0.999 \\
804\end{array}$ & 30 & $\begin{array}{l}\text { Jem } \\
\text { ber }\end{array}$ & $\begin{array}{l}0.99 \\
998 \\
4\end{array}$ \\
\hline 12 & Madiun & $\begin{array}{l}0.999 \\
812\end{array}$ & 31 & Blitar & $\begin{array}{l}0.99 \\
998 \\
7\end{array}$ \\
\hline 13 & $\begin{array}{l}\text { Kota } \\
\text { Mojokerto }\end{array}$ & $\begin{array}{l}0.999 \\
848\end{array}$ & 32 & $\begin{array}{l}\text { Prob } \\
\text { oling } \\
\text { go }\end{array}$ & $\begin{array}{l}0.99 \\
998 \\
7\end{array}$ \\
\hline 14 & $\begin{array}{l}\text { Pamekasa } \\
\mathrm{n}\end{array}$ & $\begin{array}{l}0.999 \\
85\end{array}$ & 33 & $\begin{array}{l}\text { Pacit } \\
\text { an }\end{array}$ & 1 \\
\hline 15 & $\begin{array}{l}\text { Tulungagu } \\
\text { ng }\end{array}$ & $\begin{array}{l}0.999 \\
868\end{array}$ & 34 & $\begin{array}{l}\text { Mag } \\
\text { etan }\end{array}$ & 1 \\
\hline 16 & Malang & $\begin{array}{l}0.999 \\
89\end{array}$ & 35 & $\begin{array}{l}\text { Kota } \\
\text { Blitar }\end{array}$ & 1 \\
\hline 17 & $\begin{array}{l}\text { Bondowos } \\
\text { O }\end{array}$ & $\begin{array}{l}0.999 \\
896\end{array}$ & 36 & $\begin{array}{l}\text { Kota } \\
\text { Mala } \\
\text { ng }\end{array}$ & 1 \\
\hline 18 & $\begin{array}{l}\text { Banyuwan } \\
\text { gi }\end{array}$ & $\begin{array}{l}0.999 \\
901\end{array}$ & 37 & $\begin{array}{l}\text { Kota } \\
\text { Pasu } \\
\text { ruan }\end{array}$ & 1 \\
\hline 19 & Kediri & $\begin{array}{l}0.999 \\
904\end{array}$ & 38 & $\begin{array}{l}\text { Kota } \\
\text { Batu }\end{array}$ & 1 \\
\hline
\end{tabular}

Tabel 4.

Tabel Hasil penghitungan BNDI Kabupaten dan Kota di Provinsi Jawa Timur tahun 2017 \begin{tabular}{|l|l|l|l|l|l|l|}
\hline $\mathbf{N}$ & Kota/K & Nilai & $\mathbf{N}$ & Kota/K & Nildi \\
\hline
\end{tabular} \begin{tabular}{ll|l|l|l|l|l|}
\hline & ab. & BNDI & 0 & ab. & BNDI
\end{tabular}

\begin{tabular}{l|l|l|l|l|l|l|}
\hline 1 & Kota & 0.998 & 20 & Lumaj & 0.999 \\
\hline
\end{tabular}

\begin{tabular}{|l|l|l|l|l|l|} 
& Madiun & 425 & & ang & 894 \\
\hline 2 & Sidoarj & 0.999 & 21 & Tulung & 0.999
\end{tabular}

\begin{tabular}{|c|l|l|l|l|l|} 
& 0 & 243 & & agung & 904 \\
\hline 3 & $\begin{array}{l}\text { Kota } \\
\text { Proboli } \\
\text { nggo }\end{array}$ & $\begin{array}{l}0.999 \\
442\end{array}$ & 22 & $\begin{array}{l}\text { Maget } \\
\text { an }\end{array}$ & $\begin{array}{l}0.999 \\
906\end{array}$ \\
\hline 4 & Kota & 0.999 & 37 & Kota & 0.999 \\
\hline
\end{tabular}

\begin{tabular}{|c|l|l|l|l|l|}
\hline 4 & Kota & 0.999 & 37 & Kota & 0.999 \\
Kediri & 467 & Blitar & 907 \\
\hline 5 & Kota & 0.999 & 23 & Situbo & 0.999 \\
\hline
\end{tabular}

\begin{tabular}{|c|l|l|l|l|l|} 
& $\begin{array}{l}\text { Suraba } \\
\text { ya }\end{array}$ & 55 & ndo & 908 \\
\hline 6 & $\begin{array}{l}\text { Kota } \\
\text { Pasurua } \\
\text { n }\end{array}$ & $\begin{array}{l}0.999 \\
573\end{array}$ & 24 & $\begin{array}{l}\text { Banyu } \\
\text { wangi }\end{array}$ & $\begin{array}{l}0.999 \\
911\end{array}$ \\
\hline 7 & $\begin{array}{l}\text { Mojoke } \\
\text { rto }\end{array}$ & $\begin{array}{l}0.999 \\
603\end{array}$ & 25 & $\begin{array}{l}\text { Sumen } \\
\text { ep }\end{array}$ & $\begin{array}{l}0.999 \\
925\end{array}$ \\
\hline 8 & $\begin{array}{l}\text { Ponoro } \\
\text { go }\end{array}$ & $\begin{array}{l}0.999 \\
609\end{array}$ & 26 & $\begin{array}{l}\text { Bangk } \\
\text { alan }\end{array}$ & $\begin{array}{l}0.999 \\
926\end{array}$ \\
\hline 9 & $\begin{array}{l}\text { Bojone } \\
\text { goro }\end{array}$ & $\begin{array}{l}0.999 \\
659\end{array}$ & 27 & $\begin{array}{l}\text { Pasuru } \\
\text { an }\end{array}$ & $\begin{array}{l}0.999 \\
94\end{array}$ \\
\hline 10 & $\begin{array}{l}\text { Nganju } \\
\text { k }\end{array}$ & $\begin{array}{l}0.999 \\
682\end{array}$ & 28 & $\begin{array}{l}\text { Samp } \\
\text { ang }\end{array}$ & $\begin{array}{l}0.999 \\
943\end{array}$ \\
\hline 11 & $\begin{array}{l}\text { Jomba } \\
\text { ng }\end{array}$ & $\begin{array}{l}0.999 \\
723\end{array}$ & 30 & Ngawi & $\begin{array}{l}0.999 \\
953\end{array}$ \\
\hline 12 & $\begin{array}{l}\text { Trengg } \\
\text { alek }\end{array}$ & $\begin{array}{l}0.999 \\
751\end{array}$ & 31 & Tuban & $\begin{array}{l}0.999 \\
959\end{array}$ \\
\hline 13 & Gresik & 0.999 \\
79 & 32 & $\begin{array}{l}\text { Jembe } \\
\text { r }\end{array}$ & $\begin{array}{l}0.999 \\
965\end{array}$ \\
\hline 14 & Kediri & 0.999 \\
808 & 33 & $\begin{array}{l}\text { Lamon } \\
\text { gan }\end{array}$ & $\begin{array}{l}0.999 \\
965\end{array}$ \\
\hline 15 & Madiun & 0.999 & 34 & Proboli & 0.999 \\
\hline
\end{tabular}



DEFICIENCY INDEX (BNDI)

\begin{tabular}{|l|l|l|l|l|l|}
\hline & & 832 & & nggo & 987 \\
\hline 16 & $\begin{array}{l}\text { Pamek } \\
\text { asan }\end{array}$ & $\begin{array}{l}0.999 \\
84\end{array}$ & 35 & Blitar & 1 \\
\hline 17 & Malang & $\begin{array}{l}0.999 \\
859\end{array}$ & 36 & $\begin{array}{l}\text { Pacita } \\
\mathrm{n}\end{array}$ & 1 \\
\hline 18 & $\begin{array}{l}\text { Kota } \\
\text { Mojoke } \\
\text { rto }\end{array}$ & $\begin{array}{l}0.999 \\
86\end{array}$ & 37 & $\begin{array}{l}\text { Kota } \\
\text { Malan } \\
\text { g }\end{array}$ & 1 \\
\hline 19 & $\begin{array}{l}\text { Bondo } \\
\text { woso }\end{array}$ & $\begin{array}{l}0.999 \\
876\end{array}$ & 38 & $\begin{array}{l}\text { Kota } \\
\text { Batu }\end{array}$ & 1 \\
\hline \multicolumn{3}{|l|}{ Hasil } & BNDI yang tinggi atau \\
\hline
\end{tabular}

mendekati angka 1 (satu) menunjukan zakat yang didistribusikan oleh Badan Amil Zakat Nasional Provinsi Jawa Timur tidak efektif untuk mengurangi kemiskinan di Jawa Timur, dikarenakan zakat yang didistribusikan tidak sebanding dengan minimal pengeluaran untuk kebutuhan dasar pada wilayah tersebut, bahkan ada beberapa Kota maupun Kabupaten yang belum terdistribusi zakat, hal ini dikarenakan tidak adanya BAZNAS kota maupun Kabupaten. Meskipun jumlah zakat yang didistribusikan oleh Badan Amil Zakat Provinsi Jawa Timur cenderung meningkat dari tahun ke tahun namun tetap saja tidak mampu untuk memenuhi minimum kebutuhan dasar orang miskin diwilayah tersebut, dikarenakan angka garis kemiskinan yang semakin meningkat dari tahun-ketahun. Berikut hasil alalisis BNDI tahun 2017 :

\section{BNDI Tertinggi}

BNDI tertinggi yang dimaksud adalah empat kota atau kabupaten dengan BNDI tertinggi setelah nilai satu, diantaranya ; Kab.Lamongan,
Kab.Banyuwangi, Kab.Jember, Kab.probolinggo. BNDI tinggi atau mendekati angka 1 (satu)menunjukan hasil yang tidak baik.

\section{Kab.probolinggo}

Kab.Probolinggo memiliki luas daerah $1.696 \mathrm{~km}^{2}$ dan memiliki jumlah penduduk 1.127 juta jiwa. Pada tahun 2017, garis kemiskinan Kab.Probolinggo sebesar Rp384.343 dan jumlah orang miskin sebanyak 236.720 jiwa, zakat yang didistribusikan BAZNAS provinsi Jawa Timur hanya untuk tiga orang dengan nilai zakat masing-masing Rp400.000, total jumlah zakat yang didistribusikan BAZNAS provinsi Jawa Timur sebesar Rp1.200.000, dengan rumus BNDI, dimana BNDI $=1-\frac{G_{Z}}{E_{B}}, \mathrm{Gz}$ adalah zakat yang didistribusikan oleh BANAS provinsi Jawa Timur yaitu sebesar Rp1.200.000 sedangkan EB adalah jumlah minimum kebutuhan dasar pada wilayah tersebut (garis kemiskinan $\mathrm{x}$ jumlah orang miskin pada wilayah tersebut) hasil penghitungan BNDI sebesar 0.999987, menyatakan posisi Kabupaten Probolinggo dengan BNDI tertinggi pertama, dari tahun 2015 sampai 2017 Kab.probolinggo konsisten dengan 4 besar kategori BNDI tertinggi. Dikarenakan zakat yang didistribusikan tetap sama dari tahun ketahun.

\section{Kab.Lamongan}

Kab.Lamongan memiliki luas daerah $1.782 \mathrm{~km}^{2}$ dan memiliki jumlah penduduk 1.212 juta jiwa. Pada tahun 2017, garis kemiskinan Kab.Lamongan sebesar Rp335.783 dan jumlah orang miskin 
sebanyak 171.380 jiwa, zakat yang didistribusikan BAZNAS provinsi Jawa Timur hanya untuk lima orang dengan nilai zakat Rp400.000, dengan total jumlah zakat yang didistribusikan sebesar Rp2.000.000, dengan rumus BNDI, dimana $\mathrm{BNDI}=1-\frac{G_{Z}}{E_{B}}, \mathrm{Gz}$ adalah zakat yang didistribusikan oleh BANAS provinsi Jawa Timur yaitu sebesar Rp2000.000 sedangkan EB adalah jumlah minimum kebutuhan dasar pada wilayah tersebut (garis kemiskinan $\mathrm{x}$ jumlah orang miskin pada wilayah tersebut) hasil penghitungan BNDI sebesar 0.999965, menyatakan posisi Kabupaten Lamongan dengan BNDI tertinggi setelah Kab.Probolinggo. Dari tahun 2015 sampai 2017 Kab.Lamongan konsisten dengan 4 besar kategori BNDI tertinggi. Dikarenakan zakat yang didistribusikan tidak mengalami kenaikan yang signifikan dari tahun ketahun. Buruknya, jika di tahun 2016 Kab.Lamongan peringkat keempat BNDI tertinggi (terburuk), ditahun 2017 naik menjadi peringkat kedua.

\section{Kab.Jember}

Kab.Jember memiliki luas daerah $1.839,94 \mathrm{~km}^{2}$ dan memiliki jumlah penduduk 1,154 juta jiwa. Pada tahun 2017, garis kemiskinan Kab.Jember sebesar Rp310.650 dan jumlah orang miskin sebanyak 266.900 jiwa, zakat yang didistribusikan BAZNAS provinsi Jawa Timur hanya untuk delapan orang dengan nilai zakat masing-masing Rp400.000 dan Rp250.000, dengan total jumlah zakat yang didistribusikan Rp2.900.000, dengan rumus BNDI, dimana BNDI $=1-\frac{G_{Z}}{E_{B}}, \mathrm{Gz}$ adalah zakat yang didistribusikan oleh BANAS provinsi Jawa Timur yaitu sebesar Rp2.900.000 sedangkan EB adalah jumlah minimum kebutuhan dasar pada wilayah tersebut (garis kemiskinan $\mathrm{x}$ jumlah orang miskin pada wilayah tersebut) hasil penghitungan BNDI sebesar 0.999965, menyatakan posisi Kabupaten Jember dengan BNDI tertinggi kedua seperti Kab.Lamongan. Dari tahun 2015 Kab.Jember konsisten dengan peringkat empat besar BNDI tertinggi, meskipun ditahun 2016 adanya peningkatan jumlah zakat dibanding tahun 2015 yang hanya Rp900.000, dan ditahun 2017 menjadi Rp2.900.000. hal yang mempengaruhi tentunya angka garis kemiskinan yang semakin meningkat dan adanya kota/kab. Lain yang juga mulai mendapatkan distribusi zakat.

\section{Kab.Tuban}

Kab.Tuban memiliki luas daerah $1.782 \mathrm{~km}^{2}$ dan memiliki jumlah penduduk 1.212 juta jiwa. Pada tahun 2017, garis kemiskinan Kab.Tuban sebesar Rp308.822 dan jumlah orang miskin sebanyak 196.100 jiwa, zakat yang didistribusikan BAZNAS provinsi Jawa Timur hanya untuk tujuh orang dengan nilai zakat masing-masing Rp400.000 dan Rp250.000, dengan total jumlah zakat yang didistribusikan BAZNAS provinsi Jawa Timur sebesar Rp2.500.000, dengan rumus $\mathrm{BNDI}$, dimana $\mathrm{BNDI}=1-\frac{G_{Z}}{E_{B}}, \mathrm{Gz}$ adalah zakat yang didistribusikan oleh BANAS provinsi Jawa Timur yaitu sebesar Rp2.500.000 sedangkan EB adalah jumlah 
minimum kebutuhan dasar pada wilayah tersebut (garis kemiskinan $x$ jumlah orang miskin pada wilayah tersebut) hasil penghitungan BNDI sebesar 0.999959, menyatakan posisi Kabupaten Tuban dengan BNDI tertinggi urutan ke-4. Untuk Kab.Tuban, pada tahun 2015 menempati urutan ke-8 BNDI tertinggi, dan ke-6 pada tahun 2016, sedangkan tahun 2017 menempati urutan ke 4, semakin tahun hasil dari BNDI semakin buruk. Pada tahun $2016 \mathrm{Kab}$. Tuban mendapat distribusi zakat Rp1.400.000, lebih rendah dari tahun 2015 yang mencapai Rpl.800.000, meskipun ditahun 2017 ada peningkatan jumlah zakat yang didistribusikan namun tidak mampu membuat peringkan Kab.Tuban lebih baik.

\section{BNDI Terendah}

Semakin rendah BNDI menunjukan hasil yang semakin baik, pada tahun 2017 nilai BNDI terendah diantaranya; Kota Madiun, Kab.Sidoarjo, Kota Probolinggo, Kota Kediri dan Kota Surabaya.

\section{Kota Madiun}

Memiliki luas daerah $65.68 \mathrm{~km}^{2}$ dan memiliki jumlah penduduk 170.964 jiwa. Pada tahun 2017, garis kemiskinan Kota Madiun sebesar Rp404.959 dan jumlah orang miskin sebanyak 8.700 jiwa, zakat yang didistribusikan BAZNAS provinsi Jawa Timur hanya untuk 15 orang dengan nilai zakat masing-masing Rp400.000 dan Rp250.000, dengan total jumlah zakat yang didistribusikan oleh BAZNAS provinsi jawa Timur Rp 5.550.000, dengan rumus $\mathrm{BNDI}$, dimana BNDI $=1-\frac{G_{Z}}{E_{B}} \mathrm{Gz}$ adalah zakat yang didistribusikan oleh BANAS provinsi Jawa Timur yaitu sebesar Rp5.550.000 sedangkan EB adalah jumlah minimum kebutuhan dasar pada wilayah tersebut (garis kemiskinan $\mathrm{x}$ jumlah orang miskin pada wilayah tersebut) hasil penghitungan BNDI sebesar 0.998425, menyatakan posisi Kota Madiun dengan BNDI terendah urutan pertama. Kota Madiun konsisten menempati urutan empat besar BNDI terendah dari tahun 2015-2017, ini hal yang positif. Meskipun jika kita mengacu pada data, zakat yang didistribusikan tidaklah sebanyak Kab.Sidoarjo maupun kota Surabaya. Namun, garis kemiskinan yang lebih rendah dari kab.Sidoarjo dan Kota Surabaya, juga karena jumlah orang miskin yang lebih sedikit dibandingkan dengan Kab.Sidoarjo dan Kota Surabaya membawa Kota Madiun urutan pertama ditahun 2016 dan 2017.

\section{Kab.Sidoarjo}

Kab.Sidoarjo memiliki luas daerah $634.4 \mathrm{~km}^{2}$ dan memiliki jumlah penduduk 2,279 juta jiwa. Pada tahun 2017, garis kemiskinan Kab.Sidoarjo sebesar Rp414.479 dan jumlah orang miskin sebanyak 135.420 jiwa, zakat yang didistribusikan BAZNAS provinsi Jawa Timur untuk 125 orang dengan nilai zakat masing-masing Rp400.000 dan Rp250.000 , dengan total jumlah zakat yang didistribusikan BAZNAS provinsi Jawa Timur sebesar Rp42.500.000, jumlah zakat ini tertinggi dbanding dengan kabupaten atau kota lainnya di Provinsi Jawa Timur 
tahun 2017. .Dengan rumus BNDI, dimana BNDI $=1-\frac{G_{Z}}{E_{B}}, \mathrm{Gz}$ adalah zakat yang didistribusikan oleh BANAS provinsi Jawa Timur yaitu sebesar Rp42.500.000 sedangkan EB adalah jumlah minimum kebutuhan dasar pada wilayah tersebut (garis kemiskinan $\mathrm{x}$ jumlah orang miskin pada wilayah tersebut) hasil penghitungan BNDI sebesar 0.999243, menyatakan posisi Kabupaten Sidoarjo dengan BNDI terendah kedua. Meskipun pendistribuan zakat terbanyak namun, Kab.Sidoarjo tidak menempati urutan pertama BNDI terendah dikarenakan faktor jumlah orang miskin dan garis kemiskinan di wilayah tersebut.Namun demikian, Kab.Sidoarjo konsisten menempati urutan empat besar BNDI terendah dari tahun 2015-2017, ini hal yang positif. Faktor yang mempengaruhi adalah jumlah zakat yang didistribusikan oleh BAZNAS Provinsi Jawa Timur terbanyak untuk kab.Sidoarjo meskipun pada tahun 2017 jumlahnya menurun namun tidaklah signifikan,salah satu faktor yang mempengaruhi karena ada beberapa mustahik yang sudah wafat.

\section{Kota Probolinggo}

Kota Probolinggo memiliki luas daerah $56.67 \mathrm{~km}^{2}$ dan memiliki jumlah penduduk 196.957 jiwa. Pada tahun 2017, garis kemiskinan Kota Probolinggo sebesar Rp437.392 dan jumlah orang miskin sebanyak 18.230 jiwa, zakat yang didistribusikan BAZNAS provinsi Jawa Timur untuk 13 orang dengan nilai zakat masingmasing Rp400.000 dan Rp250.000, total jumlah zakat yang didistribusikan BAZNAS provinsi Jawa Timur sebesar Rp4.450.000, dengan rumus BNDI, dimana BNDI = $1-\frac{G_{Z}}{E_{B}}$, Gz adalah zakat yang didistribusikan oleh BANAS provinsi Jawa Timur yaitu sebesar Rp4.450.000 sedangkan EB adalah jumlah minimum kebutuhan dasar pada wilayah tersebut (garis kemiskinan $\mathrm{x}$ jumlah orang miskin pada wilayah tersebut) hasil penghitungan BNDI sebesar 0.999442, menyatakan posisi Kota Probolinggo dengan BNDI terendah ketiga. Ini menunjukan hal yang positif karena setiap tahun nilai BNDI semakin rendah, dan tentunya setiap tahun juga diikuti dengan peringkat yang semakin tinggi untuk kategori BNDI terendah. Ditahun 2015 Kota probolinggo sempat menempati urutan ke-11, namun ditahun 2016 dan 2017 berhasil menduduki urutan ke-4 dan ke-3. Salah satu faktor yang mempengaruhi karena jumlah zakat yang didistribusikan meningkat cukup signifikan dari tahun ke tahun.

\section{Kota Kediri}

Kota Kediri memiliki luas daerah $63.40 \mathrm{~km}^{2}$ dan memiliki jumlah penduduk 267.435 jiwa. Pada tahun 2017, garis kemiskinan Kota Kediri sebesar Rp420.712 dan jumlah orang miskin sebanyak 24.070 jiwa, zakat yang didistribusikan BAZNAS provinsi Jawa Timur untuk 15 orang dengan nilai zakat masing-masing Rp400.000 dan Rp250.000 , total jumlah zakat yang didistribusikan BAZNAS provinsi Jawa Timur sebesar Rp5.400.000, dengan rumus BNDI, dimana BNDI $=1-\frac{G_{Z}}{E_{B}}, G z$ adalah zakat yang 
Fatmawati, et al/Jurnal Ekonomi Syariah Teori dan Terapan Vol. 6 No. 3 Maret 2019: 568-583; EFEKTIVITAS ZAKAT DALAM MENGURANGI KEMISKINAN DI JAWA TIMUR MENGGUNAKAN TEKNIK BASIC NEEEDS DEFICIENCY INDEX (BNDI)

didistribusikan oleh BANAS provinsi Jawa Timur yaitu sebesar Rp5.400.000 sedangkan EB adalah jumlah minimum kebutuhan dasar pada wilayah tersebut (garis kemiskinan $x$ jumlah orang miskin pada wilayah tersebut) hasil penghitungan BNDI sebesar 0.999467, menyatakan posisi Kota Kediri dengan BNDI terendah keempat.kota Kediri perbedaan BNDI dari tahun ketahun cukup signifikan, bermula dari tahun 2015 yang sama sekali tidak terdistribusi zakat, sehingga BNDI bernilai 1 (satu), ini hal terburuk. Kemudian di tahun 2016 mulai ada pendistribusian zakat sehingga menempati urutan ke-10 dengan nilai BNDI tertinggi, dan puncaknya di tahun 2017 menempati urutan ke-4 Kota dengan BNDI terendah. Hal ini dikarenakan akat yang didistribusikan meningkat lebih dari sepuluh kali lipat dari tahun 2016.

\section{KESIMPULAN DAN SARAN}

\section{KESIMPULAN}

1. Hasil penghitungan BNDI yang menunjukan zakat yang didistribusikan Badan Amil Zakat Nasional provinsi Jawa Timur tidak efektif dalam mengurangi kemiskinan selaras dengan hasil wawancara dengan bidang pendistribusian zakat BAZNAS Jawa Timur dengan segala pemasalah yang ada dalam pendistribusian.

2. Hasil penghitungan BNDI Kota dan Kabupaten dengan nilai terendah dan tertinggi tahun 2015-2017, semakin rendah nilai BNDI maka semakin baik, begitu juga sebaliknya. Peringkat kota maupun kabupaten yang berubah menunjukan tidak konsistennya zakat yang diberikan BAZNAS Provinsi Jawa Timur kepada suatu wilayah, seperti dalam wawancara disebutkan, salah satu faktor yang mempengaruhi ada tidaknya BAZNAS di wilayah tersebut, berapa persen beroperasi BAZNAS diwilayah tersebut, selain itu jumlah mustahik yang berkurang akibat wafat juga menjadi penyebabnya.

3. Target Badan Amil Zakat Nasional provinsi Jawa Timur untuk mengurangi kemiskinan sekitar 10\% tidak tercapai, dikarenakan dalam penghitungan BNDI untuk mengurangi kemiskinan sebanyak $\quad 10 \% \quad$ diperlukan pendistribusian zakat sebanyak Rp 146.150.059.954 di tahun 2015, dan Rp 151.333.851.130 ditahun 2016 dan untuk tahun 2017 dibutuhkan Rp 157.944.218.492, sedangkan zakat yang didistribukan oleh BAZNAS Provinsi Jawa Timur Rp 1.956.600.000 ditahun 2015, Rp 2.638.200.000 ditahun 2016 dan ditahun 2017 Rp 3.187.200.000

4. Meskipun target Badan Amil Zakat Provinsi Jawa Timur untuk mengurangi kemiskinan sebanyak $10 \%$ belum tercapai, namun dalam penghitungan ditemukan di tahun 2015 butuh 75 kali lipat untuk mencapai target, di tahun 2016 butuh 57 kali lipat zakat yang didistribusikan sedangkan ditahun tahun 2017 butuh 49 kali lipat, hal ini menunjukan hasil yang positif, dan mungkin beberapa tahun lagi target 
mengantaskan kemiskinan sebanyak $10 \%$ akan tercapai.

\section{SARAN}

1. Untuk Pemerintah

a. Lebih mensupport Badan Amil Zakat Nasional dengan memberikan dana untuk operasional BAZDA di setiap kota maupun kabupaten, karena selama ini untuk operasional BAZDA diambil dari APBD, banyak pemerintah daerah yang merasa keberatan sehingga BAZDA tidak beroperasi dengan baik karena minimnya dana.

b. Membentuk badan khusus yang tugasnya memastikan bahwa zaat didistribukan dengan semestinya, memberikan peta pendistribusian untuk BAZNAS, BAZDA maupun LAZ agar tidak menyebabkan penerima ganda. Selain itu, juga bertugas untuk mendata jumlah zakat,infaq dan shadah secara terpusat, hal ini selain untuk memudahkan penelitian juga untuk memahami seberapa potensi zakat yang terserap, karena pengalaman dari peneliti, BAZNAS maupun LAZNAS tidak mengetahui data keuangan BAZDA dan LAZDA yang mereka bawahi.

c. Untuk pendistribusian agar tidak terjadi Overlapping, diberikan nomor ID atau kartu identitas data penerima agar otomatis dapat terdeteksi sudah masuk ranah BAZNAS/BAZDA/LAZ yang mana.

d. jadikan zakat sebagai salah satu solusi untuk mengurangi kemiskinan, sehingga pemerintah bisa serius untuk memaksimalkan potensi zakat

2. Untuk BAZNAS

a. Bekerja lebih professional agar pemerintah setempat percaya dengan BAZNAS dan menyediakan dana untuk pembuatan BAZDA didaerahnya

b. Lebih terbuka dan up to date di website dan media sosial lainnya, terbuka dalam hal keuangan akan membuat muzakki atau calon muzakki lebih percaya untuk memberikan zakatnya kepada BAZNAS

c. Menjembatani silaturahmi dan musyawarah yang terjadwal antar LAZNAS lainnya agar tetap bersinergi untuk mengentaskan kemiskinan.

d. Adanya pemasangan target untuk mengentaskan kemiskinan sebanyak 10\% diJawa timur juga harus dibarengi dengan langkah-langkah yang akan diambil guna mencapai target tersebut.

e. Visi Misi dan tujuan tidak hanya sekedar menjembatani pendistribusian zakat namun harapannya, mengentasan kemiskinan juga menjadi point visi dan misi.

\section{DAFTAR PUSTAKA}

Beik, Irfan Syauqi dan Laily Dwi. 2016. Ekonomi Pembangunan Syariah. Edisi

Revisi. Depok: PT Rajagrafindo Persada.

Creswell, John. W. 2015. Research Design Second Edition. Terjemahan oleh Lintan

Lazuardi. Yogyakarta: Pustaka Pelajar. 
Fatmawati, et al/Jurnal Ekonomi Syariah Teori dan Terapan Vol. 6 No. 3 Maret 2019: 568-583; EFEKTIVITAS

ZAKAT DALAM MENGURANGI KEMISKINAN DI JAWA TIMUR MENGGUNAKAN TEKNIK BASIC NEEEDS DEFICIENCY INDEX (BNDI)

Dawson, $\quad$ Yelena. $2015 . \quad$ The Institutionalisation of Private Sector Performance

Masurement in an Australian Oot-forprofit Organisation. epublications@scu.

Fakultas Bisnis Administrasi. Southern Cross University.

Fauzia, Amelia. 2008. Faith and a State: a History of Islamic Philanthropy in

Indonesia. Disertasi tidak diterbitkan. Melbourne Faculty of Arts University of

Melbourne.

Hafidhuddin, Didin. 2002. Zakat dalam Perekonomian Modern. Jakarta: Gema Insani.

Hafidhuddin dan Rahmad Pramulya. 2008. Kaya Karena Berzakat. Depok : Raih Asa

Sukses.

Huda, Nurul, dkk. 2012. Kebijakan Publik Islami. Jakarta: Kencana Prenada Media

Group..

Karim, Adiwarman Azwar. 2010. Sejarah Pemikiran Ekonomi Islam. Edisi Ketiga.

Jakarta: Rajawali Press.

BAZNAS Provinsi Jawa Timur, Profil BAZNAS,

(Online), (www.baznasjatim.or.id 15 Agustus 2018. 20:17)

Badan Pusat Statistik (Online), (www.bps.go.id 15 September $20182012: 431$
Badan Pusat Statistik Provinsi Jawa Timur (online), (www.jatim.bps.go.id 15 september 2018 15:50)

Indonesia Investment (online),

(www.indonesia-investments.com

15 September 2018 16:30)

Naziruddin, dkk. (2006). The Effectiveness of zakat in alleviating poverty and inequalities ( a measurement using a newly developed technique)

Qardhawi, Yusuf. 1988. Figh al-Zakah. Bogor : Pustaka Lintera Antar Nusa Qardhawi, Yusuf. 1996. Hukum Zakat. Bogor: Pustaka Lintera Antar Nusa Republik Indonesia. Undang-Undang No 38 Tahun 1999 tentang Pengelolaan Zakat.

1999: Kementerian Agama. Undang-Undang No 23 Tahun 2011 tentang Pengelolaan

Zakat. 2011 : Diperbanyak oleh BAZNAS. PP No 14 Tahun 2014 tentang Penjelasan UU No 23 Tahun

2011 Pengelolaan Zakat. 2014: Diperbanyak oleh BAZNAS

Wibisono, Yusuf. 2015. Mengelola Zakat Indonesia. Jakarta: Kencana Prenamedia

Group

Yin, Robert K. 2014. Case Study Research: Design and Method. Terjemahan oleh $M$.

Djauzi Mudzakir. Jakarta: PT Rajagrafindo Persada. 